\title{
Uma Breve História da Leitura no Século XX, ou de Como Se Podem Calar as Nativas
}

\section{Clarissa Menezes Jordão}

\author{
Universidade Federal do Paraná
}

\begin{abstract}
This paper examines three moments of reading in education, focusing on the pedagogy of possibility, an attitude more than an approach, based on postmodern concepts. The reader and the reading process are seen either as mono- or poliphonic, according to the values attached to the notions of conflict and heterogeneity in the classroom.
\end{abstract}

KEY WORDS: conflict, possibility, interpretation, postmodernity, heterogeneity.

RESUMO: historicamente, o leitor é construído como mono ou polifônico, conforme sejam os valores vinculados às noções de conflito e heterogeneidade em sala de aula. Este texto examina três momentos da leitura na escola, concentrando-se na pedagogia da possibilidade, uma concepção pós-moderna vista mais como uma atitude do que como abordagem.

PALAVRAS-CHAVE: conflito, possibilidade, interpretação, pós-moderno, heterogeneidade

Este é um relato de percepções individuais sobre concepções de leitura através dos tempos modernos; é um relato que quer fugir um pouco (mas não muito) de convenções de escritos acadêmicos, convenções também individualmente percebidas através de leituras de autores/as em sua individualidade coletivamente constituída. Examinarei conceitos na esperança de não estabelecer compromisso com teorias renomadas ou facilmente categorizáveis no espectro (tanto fantasmagórico quanto axiomático) das teorias de educação, da lingüística ou da crítica literária. Peço ao leitor/a que se compadeça da escritora, já que ambos são seres fragmentados pelo inconsciente lacaniano e pela temática pós-moderna, e que procure no texto quem o escreve, e ainda a intenção de quem o escreve, e se sobrar tempo, que o leitor/a busque os pressupostos dos muitos textos aqui presentes, dos/as autores/as imediatos/as assim como dos/as implícitos/as na polifonia da linguagem; que o/a leitor/a entenda a opção por não usar mais /a na escritura mas, ao invés disso, utilizar, sempre que a língua portuguesa permita (numa pressuposição de que partilhamos, eu e você, deste mesmo sistema lingüístico que convencionalmente chamamos por esse nome), simplesmente o a, sem barras, solto da prisão onde ainda se encontra no mais das vezes. A fênix mitológica morre na la, e renasce no gênero feminino; daí a opção em usar, daqui por diante, o gênero feminino como generalizador. 


\section{A Leitora e a Fênix}

Primeira metade do século XX, línguas estrangeiras na escola. A aula de gramática de língua inglesa corre fluida: a professora traduz, escreve no quadro, as alunas copiam atentas (ou não muito). A professora dita, as alunas escrevem (talvez fosse melhor dizer copiam) para decorar depois. Perguntas? A professora sabe as respostas. Sugestões? Melhor deixar para daqui a algumas décadas; hoje, vamos escutar e reproduzir, seguindo o modelo. O texto só permite uma leitura correta, e a professora sabe qual é, porque estudou mais, leu mais, e afinal é a professora, selecionada pela instituição dentre outras candidatas, julgada a melhor e autorizada pela hierarquia. Ela, assim como a autora do texto, sabe o que "o texto" quer dizer, e o consenso se estabelece através da autorização que o saber, aliado à legitimação pelo poder, confere às palavras da autoridade máxima em sala de aula (fora dali a questão muda um pouco de figura: há a coordenação, a direção, as autoridades militares e políticas, o governo, a religião, a tradição - muitos caciques ...). A verdade existe e prevalece no consenso instituído pelo poder; o sucesso do ensino é proporcional à homogeneidade atingida (imposta). Aprender é assimilar e reproduzir, é manter a estrutura do conhecimento em rédeas curtas, é controlar instintos, subjugar a criatividade, estabilizar e mesmificar. Como o avestruz, fecham-se os olhos para a pluralidade em busca de uma homogeneidade aparente e artificial, imposta pelo sistema que se tenta legitimar através da manutenção da ordem, como se esta "ordem" fosse natural e vivesse em constante ameaça: tanto não é dada nem natural, que precisa ser estabelecida e então "mantida". A aparente certeza que se instaura como fruto do conhecimento conforta, fornece bases sólidas, estrutura; adapta, conforma, satisfaz aqueles que procuram absolutos, e a escola ensina a buscá-los sempre. A sociedade ensina a pensar a verdade em termos absolutos, a cultura ensina a valorizar o que se faz (e se diz) eterno; a história tradicional ensina a pensar na vida como uma busca pelo imutável, pelo perene, pelo que se mantém igual através dos tempos. Tudo se volta contra aqueles que percebem possibilidades de mudança ou deliram sobre uma possível ausência de paradigmas. As instituições são contra os que se opõem à "ordem" estabelecida como natural: a escola castiga e expulsa, a ciência não lhes dá ouvidos, a cultura classifica de "marginal" ou menor, a história trata de ignorar. Quem não se adapta é pernicioso, a menina indisciplinada não merece a atenção ou os cuidados da professora: ou a aluna se cala e conforma, ou sai da escola, do mercado de trabalho, dos círculos do saber, da sociedade.

Mas isso foi nos idos do início do século. Lá por meados dele, há já talvez muitas alunas indisciplinadas que forçam a atenção para elas: faz-se preciso então olhar com mais cuidado para saber o que leva a escola ao fracasso, para saber por quê, mesmo com professoras altamente capacitadas no conhecimento de suas matérias, muitas alunas ainda se mostram "a prova de ensino", rebeldes.

Acontece então o advento da abordagem comunicativa, quando tudo muda em sala de aula: o foco da educação agora são o sujeito e suas relações interpessoais, nas quais as diferenças são vistas como positivas e motivação e intenção são conceitos fundamentais. A 
verdade é relativa, a autoridade nos processos de significação também: cada um pode elaborar sua própria leitura, dentro de seu universo particular, e essa leitura terá o mesmo valor de verdade que qualquer outra; um texto permite inúmeras leituras, pois quem lê é que determina a interpretação. Estamos no âmbito da "reader-response", onde a aluna leitora se torna o centro do processo, e o locus da significação[i]. Ainda, portanto, há consenso, pois onde cada um determina sua interpretação não é preciso haver discussão, negociação ou acordo - aceita-se tudo e a homogeneidade é mantida em meio à diferença, ou seja, não há conflito mesmo em meio à diversidade.

Todavia, o espírito pós-moderno chega para semear o caos, para dividir e não apaziguar; ele traz a espada e não a paz. Com ele, os papéis deixam de ser fixos e estáveis: problematizam-se a produção/criação de significados e o locus da significação, que da autora desloca-se para o texto; do texto para a leitora; da leitora passa pela comunidade, por relações de poder, pela cultura, pela história, por comunidades interpretativas, adquirindo uma ubiqüidade que individualiza ao mesmo tempo em que generaliza. Cada leitora é vista como locus particular de um cruzamento de fatores de ordens diversas, o que faz de cada indivíduo um ser único e ao mesmo tempo coletivo, um ser social e ao mesmo tempo individual em seus processos de significação, em sua maneira de conferir sentido ao mundo. Questionam-se os limites da interpretação e sua legitimidade, questionam-se os papéis de quem interpreta e de quem produz interpretações, o papel da cultura, do poder, da história e da sociedade, tanto em aspectos gerais da hermenêutica quanto no processo de leitura textual.

A atenção se alarga e amplia seu foco na simultaneidade dos elementos que constituem a sala de aula. Preocupam agora não apenas a materialidade que se objetiva fisicamente, mas também elementos de mais difícil alcance pela ciência positivista, como valores, atitudes, fatores culturais, psicológicos, cognitivos, etc., que não podem ser manipulados para experimentações científicas convencionais. Admite-se a discursividade da ciência, compreendese a afirmação de Derrida de que “il n'y a pas de hors texte". Se tudo é discurso, construção, então argumentações, dentro dos moldes aceitos e legitimados pela ciência vigente, são verdades: existem, fazem existir através do uso das convenções que regem os métodos cientííicos predominantes no grupo do qual se busca a aceitação. Porém não basta estar dentro das normas do discurso acadêmico para obter "valor": tratam-se mais de questões de poder do que de verdade quando se fala em legitimação (cf. Bourdieu (1989):157-183) . Não se almeja mais a homogeneidade, que reflete imposição: valorizam-se as diferenças em seus aspectos criativos de produção.

A educação, para os teóricos pós-modernos, assume então outro papel: o de informar, mostrar, desnudar, ensinar as regras do jogo não apenas para que sejam seguidas, mas principalmente para que possam ser modificadas[ii]. Surge a pedagogia da possibilidade, ou seja, o ensino/aprendizagem de 
Possibilidade aqui não se refere a autonomia e liberdade incondicionais, como fazia o projeto educacional moderno, dentro do paradigma iluminista da igualdade e da liberdade totais, mas sim a "opções disponíveis em uma situação quando se consideram simultaneamente tanto o 'encorajamento coercivo' de determinadas formas, quanto o alcance limitado das capacidades que tais formas encorajam." (Simon (1992):21). A prática pedagógica é vista como processo "dedicado a fomentar a possibilidade através da implementação de modos de compreensão e ação que encorajem a transformação de relações específicas entre formas sociais e capacidades humanas, e assim permitam a expansão do escopo de identidades sociais em que as pessoas possam se transformar" (Simon (1992):22). Admite-se o poder das trocas simbólicas de que fala Bourdieu (1982), e como conseqüência, estimula-se na educação a compreensão e a transformação desse poder.

O sujeito passa de único a fragmentado, sendo visto em sua individualidade como um ser em relação, ou seja, como constituído através e a partir de inter-relações não apenas entre indivíduos, mas também entre poderes, classes, etnias, grupos, mercados, ideologias, etc. A leitura é um processo de interpretação tão fragmentado quanto o sujeito, tão determinado por inter-relações quanto o mundo dos signos, tão distante de interpretações absolutas quanto os valores culturais. Leituras não têm mais a verdade, o texto, o autor, o professor como parâmetros para legitimação, sendo contrapostas agora às comunidades interpretativas, às estruturas de poder, ao pensamento dominante, aos ditames de linhas interpretativas vigentes; interpretações legítimas são aquelas que correspondem ou transformam processos interpretativos aceitos como verdadeiros dentro de um grupo social específico, e para tanto, devem ou submeter-se às normas vigentes ou modificá-las.

A modificação do já legitimado, porém, demanda paciência e sagacidade: além de criatividade e inteligência, o agente transformador precisa sempre levar em conta o já existente, provar-se capaz dentro das normas vigentes, e transformar a partir do que já existe, pois a criação absolutamente original, em que signos não teriam relação com outros pré-existentes, é impensável[iii]. A própria linguagem é sempre um relacionar de significados, e processos de significação são jogos de differánce (Derrida (1976 e 1995)). Todas as leituras são possibilidades de leituras, mas apenas algumas serão "legítimas", quer dizer, apenas algumas serão aceitas como válidas dentro de determinada comunidade interpretativa.

A escola, portanto, ao trabalhar nessa perspectiva com leitura de textos escritos, tem por objetivo oportunizar o domínio das normas e ao mesmo tempo a possibilidade de transformação delas. É sua função possibilitar às alunas o controle dos valores estabelecidos nas e pelas comunidades de que querem participar, assim como propiciar o desenvolvimento de um olhar crítico que se reflita sobre essas mesmas comunidades, fomentando a transformação. A escola pós-moderna tem sim a emancipação como objetivo, mas não mais uma emancipação ingênua 
que acredita na independência do Homem pensante, na supremacia do Homo Sapiens diante da natureza e das estruturas sociais criadas por ele mesmo. A emancipação de que se fala aqui refere-se ao conhecimento e domínio das normas contingencialmente estabelecidas por determinados grupos sociais; acredita-se que a partir desse conhecimento seja possível propiciar transformações das normas, mudanças, alargamento dos limites impostos pelas sociedades.

O ensino de literaturas de língua inglesa porém parece-me estar embasado nos moldes modernos, em que a autoridade encontra-se na leitura da professora (que geralmente também é a dos críticos literários autorizados pela academia). Tenho observado aulas sistematicamente, e entrevistado alunas e professoras. Para minha surpresa, existe uma crença generalizada em uma harmonia quase que absoluta entre alunas e professoras, tanto em relação às causas das dificuldades enfrentadas quanto a possíveis soluções para os problemas encontrados, problemas esses sempre atribuídos a deficiências na formação intelectual e no pensamento analítico das alunas. A idéia parece ser de que, uma vez que as "falhas" têm origem no passado, na escolarização deficiente a que se submeteram as alunas, pouco se pode fazer para solucioná-las ou minimizar seus efeitos; falta leitura, experiência de análise literária, conhecimento de mundo, de teoria da literatura, enfim, lacunas que não podem ser supridas em um semestre. O que resta, então, é conformar-se com a situação e tentar fazer do sofrimento inevitável um fardo menos pesado. Tenta-se assim encontrar textos (canônicos, pois os programas das disciplinas assim o exigem) "acessíveis" ao pouco conhecimento das alunas, e demonstrar a importância dos estudos literários através de análises de textos e panoramas históricos que convençam sobre a significação e o valor da literatura na sociedade. Em sala de aula, quando se fala em análise, interpretação, leitura, ensaios acadêmicos, textos, tem-se em mente uma perspectiva positivista, em que não se discutem possibilidades de outras possibilidades. Assume-se uma uniformidade de conceitos que supostamente garante a comunicação, excluindo por antecipação conceitos que divergem da "norma". Transparece a noção de leitura/interpretação como conseqüência de reflexão analítica dentro da lógica positivista de causa/efeito, em que uma única linha interpretativa é aceita como "verdade". Essa linha única permite sim algumas variações para acomodar traços das idiossincrasias interpretativas, mas qualquer tentativa de leitura que não se enquadre no habitus (Bourdieu:1982, 1989), nos parâmetros previa e tacitamente estabelecidos é simplesmente taxada de "incorreta" e ignorada, tanto pelas alunas quanto pelas professoras. O conceito derridiano de texto como processo de significação, como modo de criar/fazer sentido do mundo não existe nas aulas de literatura: os textos literários são circunscritos às folhas de papel impresso, vistos como "dados", e a participação do leitor na construção dos significados simplesmente inexiste. Há a crença de que os textos escritos trazem consigo significados que precisam ser "decodificados" pelos leitores, quer dizer, pela professora, e transmitidos às alunas.

A sala de aula de literaturas de língua inglesa me parece uma projeção de um mundo moderno em que se busca a harmonia, a homogeneidade, o consenso. Um mundo onde existe uma verdade, um significado, uma realidade independente e exterior ao sujeito. A inabilidade ou incapacidade (talvez impossibilidade) de reprodução do sistema por parte das alunas é 
interpretada como falta de conhecimento, tanto por elas quanto por suas professoras. Cria-se assim uma relação de dependência na qual cabe à professora o papel de "transmitir", e às alunas o de "receber/reproduzir". Nessa visão, a literatura "cria" significados, ou melhor, codifica mensagens que os textos literários transmitem; o processo de significação é exterior, independente, absoluto. Não se trabalham possibilidades, não se discutem alternativas, não se questionam procedimentos interpretativos, não se transformam processos de formação de sujeitos. Ora, cada indivíduo faz sentido do mundo, e conseqüentemente constrói textos, de uma maneira própria, que é o resultado da posição que ocupa dentro das várias comunidades interpretativas em que se insere. Assim sendo, há sempre aspectos coletivos e individuais em qualquer leitura. Porém, nas aulas de literatura que tenho observado, e nas que me lembro de ter dado, as alunas limitam sua participação à confirmação dos aspectos coletivos nas interpretações. As leituras individuais, as contribuições únicas vindas dos universos particulares, não são expostas, e talvez nem cheguem a ser percebidas objetivamente. Daí a aparente harmonia que se estabelece, em que todos acabam "concordando" com todos, o que impede que ocorra a aprendizagem como processo de construção, de resistência, de percepção de possibilidades.

Dentro da perspectiva de conhecimento como algo que nunca se completa, que é sempre parcial e localizado, espero que este artigo não tenha oferecido respostas, mas ao invés disto lançado dúvidas, oportunizado questionamentos, "criado" problemas; espero que ele tenha possibilitado interpretações, criado conflitos, permitido a dúvida. Ao fazermos aparecerem os insetos na grama que nos acostumamos a ver parelha e homogênea, possibilitamos a percepção da diversidade, a consciência do diferente. Quando descemos do saber científico e olhamos de perto a grama, com os pés descalços de quem quer ver, expomo-nos à incerteza, à insegurança; percebemos a instabilidade do terreno, as texturas variadas, as oscilações de temperatura, o vento na grama, a multiplicidade. Aprendemos. Criamos. Possibilitamos.

\section{NOTAS}

\footnotetext{
[i][i] Refiro-me aqui a um extremo da "reader-response criticism", ou seja, principalmente a posições como as de Norman Holland, onde o texto é um modo de a leitora interpretar a si mesma; posições que considero conciliatórias são as de Stanley Fish e Jonathan Culler com seus leitores informados, convenções de leitura e comunidades interpretativas. Para uma comparação entre as diferentes posições dentro da "reader-response" ver EDMONDS \& SKERRET JR, 1996 e HARKER, 1996.
} 


\section{REFERÊNCIAS BIBLIOGRÁFICAS}

BAKHTIN, M. (1992) Estética da Criação Verbal. São Paulo: Martins Fontes.

. (1988) Marxismo e Filosofia da Linguagem. São Paulo: Hucitec.

BOURDIEU, P. (1982) A Economia das Trocas Simbólicas. São Paulo: Perspectiva. (1989) Pierre Bourdieu. São Paulo: Ática.

CULLER, J. (1994) On Deconstruction: theory and criticism after structuralism. London: Routledge.

DERRIDA, J. (1976) Of Grammatology. Baltimore: Johns Hopkins.

(1995) Writing and Difference. London: Routledge.

FAIRCLOUGH, N. (1992) Michel Foucault and the Analysis of Discourse In: Discourse and Social Change. Harlow: Longman.

(1989) Language and Power. Harlow: Longman.

FISH, S. (1995) Is There a Text in This Class?: the authority of interpretive communities. Cambridge: Harvard University Press, $9^{\text {th }}$ ed.

FOUCAULT, M. What's an Author? In: HARARI, J.V.(ed.) (1979) Textual Strategies. England: Methuen.

. The Order of Discourse In: RICE, P. \& WAUGH, P. (1989) Modern Literary Theory. Great Britain: Edward Arnold.

HARKER, W. Literary Theory and the Reading Process: a meeting of perspectives In: JACOBUS, L. (1996) Teaching Literature: a collection of essays on theory and practice. New Jersey: Prentice-Hall.

LYOTARD, J. (1986) O Pós-Moderno. Rio de Janeiro: José Olympio.

PENNYCOOK, A. (1994) The Cultural Politics of English as an International Language. Harlow: Longman.

SIMON, R. I. (1992) Teaching Against the Grain: texts for a pedagogy of possibility. New York: Bergin\& Garvey.

USHER, R \& EDWARDS, R. (1996) Postmodernism and Education. London: Routledge. 